\title{
ILCEA
}

Revue de l'Institut des langues et cultures

d'Europe, Amérique, Afrique, Asie et Australie

$16 \mid 2012$

La culture progressiste à l'époque de la guerre froide

\section{La música pop en la España franquista: rock, ye-ye y beat en la primera mitad de los años 60}

Pop Music in Franco's Spain: Rock, Yé-Yé and Beat in the first half of the 1960s

\section{Paloma Otaola Gonzalez}

\section{OpenEdition}

\section{Journals}

Edición electrónica

URL: http://journals.openedition.org/ilcea/1421

DOI: $10.4000 /$ ilcea.1421

ISSN: 2101-0609

\section{Editor}

UGA Éditions/Université Grenoble Alpes

\section{Edición impresa}

ISBN: 978-2-84310-232-5

ISSN: 1639-6073

\section{Referencia electrónica}

Paloma Otaola Gonzalez, «La música pop en la España franquista: rock, ye-ye y beat en la primera mitad de los años 60», ILCEA [En línea], 16 | 2012, Publicado el 04 julio 2012, consultado el 22 marzo 2021. URL: http://journals.openedition.org/ilcea/1421 ; DOI: https://doi.org/10.4000/ilcea.1421

Este documento fue generado automáticamente el 22 marzo 2021.

(C) ILCEA 


\title{
La música pop en la España franquista: rock, ye-ye y beat en la primera mitad de los años 60
}

Pop Music in Franco's Spain: Rock, Yé-Yé and Beat in the first half of the 1960s

\author{
Paloma Otaola Gonzalez
}

1 A principios de los años 1960 España comienza a vivir una época de bienestar tras las estrecheces de la posguerra. La creación de una nueva clase media y el aumento del poder adquisitivo cambiaron los hábitos y el estilo de vida de los españoles. La llegada masiva de turistas abrió las fronteras y entraron con ellos nuevos aires y nuevas modas. Al mismo tiempo, la bonanza económica permitirá a los españoles salir al extranjero y tomar contacto directamente con los modos de vida de la sociedad europea, mientras que desde el punto de vista político el Movimiento (ideario político franquista) permanecía inamovible.

2 Paralelamente al despegue económico se produjo un despertar en los jóvenes al son de la música que venía de fuera. Estas nuevas generaciones no habían vivido la guerra civil y la cartilla de racionamiento no era más que un mal recuerdo en la memoria de sus padres. La ruptura generacional, constante en todas las épocas, implicó el abandono del bolero y la canción romántica, adoptando las formas y los ritmos americanos y europeos. La música joven de esta década se llamó "música moderna", "rítmica", "yeye", siendo la expresión "música pop" la más aceptada para referirse a la música joven de este periodo.

3 El propósito de estas páginas es el de presentar un panorama no exhaustivo de las diferentes tendencias de la música pop española en los primeros años de su desarrollo (1960-1965). Aunque de gran interés, no abordaremos la nova cançò catalana ni la canción protesta contra el régimen franquista ${ }^{1}$. Trataremos en primer lugar de la eclosión de la "música moderna" española y de su difusión a través de los medios de comunicación. A continuación veremos algunas de las tendencias más destacadas y su impacto en la juventud española. 


\section{Eclosión de la música pop}

Desde finales de los años 1950, los nuevos ritmos suscitaron en el suelo español la aparición de cantantes y grupos, imitadores fieles de los modelos extranjeros, no solo americanos sino también ingleses, franceses e italianos. Con los 1960 llegaron los nuevos bailes que se sucedían a velocidad vertiginosa. Primero el rock, luego el twist, el madison al que siguió la yenka y muchos otros que se ponían de moda en verano.

5 A través de los festivales de música ligera como el de Benidorm o el del Mediterráneo, que tenían una intención claramente turística, se perpetuaba un estilo de canción melódica inspirada en el modelo francés e italiano. Al mismo tiempo, los festivales de rock y de los conjuntos, organizados al principio en los centros de enseñanza como el colegio del Pilar o el Instituto Ramiro de Maeztu de Madrid, mostraron rápidamente la preferencia de los jóvenes por los ritmos y la música anglosajona. Ante la popularidad de este tipo de manifestaciones, comenzaron a organizarse conciertos y festivales en teatros, salas de fiesta y en los pabellones de deporte, concretamente en Madrid y Barcelona. Dichos festivales eran organizados habitualmente por los programas de radio dedicados a la música moderna con el patrocinio de grandes empresas como El Corte Inglés.

6 El alcance y la rápida difusión de la música pop no hubieran sido posibles sin el apoyo de los medios de comunicación. Uno de los que más contribuyo a su desarrollo fue la radio. Entre los programas emblemáticos de esta época podemos mencionar Caravana Musical (abril 1960)². Dirigido por Ángel Álvarez, emitía sobre todo música americana, rock country, traída directamente de EEUU, gracias a sus viajes como operador de radio de Iberia. Los seguidores del programa coinciden en considerarlo como "la punta de lanza, la referencia, la apertura del país a otros ritmos, los nuevos ritmos de la música popular"3. En el programa se elaboraban listas semanales de éxitos y con los que permanecían durante 14 semanas se formaban las "Series Doradas". La conciencia de grupo de los seguidores del programa a través del "club de viajeros" sigue viva hoy en día. Inseparables de Caravana Musical fueron las sesiones matinales de los domingos en las que se reunían los jóvenes para escuchar música en directo en el Auditorio de La Voz de Madrid, en la calle Hilarión Eslava $\mathrm{n}^{\circ} 38$. Las reuniones consistían en comentarios de Ángel Álvarez a la audición de discos y también actuaciones en directo de grupos españoles que empezaban a darse a conocer. Por allí pasaron Los Pekenikes, Los Estudiantes, Dick y Los Relámpagos y muchos otros.

7 Ante el éxito de Caravana Musical, la cadena SER creó en 1963 El Gran Musical, dirigido por Tomas Martín Blanco, que se convirtió en una de las referencias musicales con un fuerte impacto en la industria discográfica. Cada domingo se reunían en el Estudio 5 de Radio Madrid unos 200 jóvenes. Se presentaban los primeros discos de las listas extranjeras y las novedades del mercado español. Muchos artistas que luego fueron famosos como Juan Manuel Serrat, María Ostiz, Luis Eduardo Aute o Víctor Manuel entre otros, obtuvieron sus primeros contratos con las casa de discos tras actuar o ser entrevistados en el programa (Pedrero Esteban, 2000, p. 33-34). Así las matinales de Caravana Musical, las de El Gran Musical, las del Price, de las que hablaremos más adelante, contribuyeron a la difusión en directo de la música pop.

8 Entre los programas de televisión, tuvo una gran audiencia entre los jóvenes Escala en Hi-fi que se emitía los domingos por la tarde. El programa estaba dedicado al mundo del 
disco de la música ligera. Los actores del programa eran jóvenes que simulaban cantar los éxitos del momento en play back.

Junto a la radio, la prensa también tuvo un papel destacado en la difusión de la música joven. Entre las revistas musicales podemos citar Discóbolo (1962-1971), Fonorama (1963-1968), revista dedicada a la "música moderna" y Fans (1965-1967).

Fonorama tenía una salida mensual en su primera época, mientras que Fans era una publicación semanal. Ambas revistas surgieron como imitación de Salut les copains. Su objetivo era crear un espacio para los jóvenes en torno a los cantantes y grupos representativos de la música moderna. En estrecha colaboración con los programas de radio, publicaban las listas del Hit-parade, según dos criterios: la popularidad y las ventas de discos. Para las listas de popularidad, los oyentes de los programas votaban sobre los discos presentados durante la semana o durante el mes.

11 Las dos publicaciones tenían una estructura similar: los cantantes de moda aparecen en las portadas y la mayor parte de sus páginas están dedicadas a entrevistas, noticias, reportajes, fotos, presentación de novedades discográficas y festivales, listas de éxitos. La portada es en color mientras que el interior suele ser en blanco y negro con un Póster central en color. El objetivo de estos pósters era que las fans pudieran decorar su habitación con las fotos de sus ídolos preferidos. Intercaladas aparecen las páginas publicitarias necesarias para mantener la publicación.

12 La mayoría de los cantantes que aparecen en Fans son extranjeros aunque también se menciona a los españoles ${ }^{4}$. La lista de famosos muestra el eclecticismo de la revista que no se centra en un único estilo de música y al mismo tiempo la falta de límites precisos en la percepción de la música moderna, donde el único criterio es el éxito y la popularidad lo que hace que un mismo número se hable con igual ardor de G. Cinquetti, de Elvis Presley, de los Rolling Stones, de Sylvie Vartan o incluso de Luis Aguilé. Una de las secciones más interesantes para tomar la temperatura de la época es el correo de lectores o "Cartas a Fans". A través de ellas nos llega la opinión de las lectoras (se trata en su mayoría de un público femenino) sobre la música moderna. En este sentido, la prensa musical de estos años constituye una fuente de primera mano para conocer el impacto de la música extranjera entre los jóvenes españoles.

Héctor Fouce afirma en su trabajo sobre la movida que en los años 1980, tras la instauración de la democracia, "por primera vez, los músicos españoles estuvieron al día de lo que se escuchaba en otros países occidentales" (Fouce, 2006, p. 19). En realidad, este fenómeno de adhesión a las modas extranjeras se produce ya 20 años antes con la eclosión de la música pop en los 1960.

14 Los programas de radio, los festivales estudiantiles y la prensa favorecieron la recepción la música ye-ye francesa, del rock americano y del beat británico, creando actitudes y sentimientos ambivalentes: por una parte la afirmación de la identidad hispánica a través de los ídolos nacionales; por otra, el deseo de emular a los cantantes y grupos de éxito internacional. Así el Dúo Dinámico fue una versión española de los Everly Brothers, los primeros Pekenikes de los Shadows, los Mustang y los Brincos de los Beatles, etc. Los cantantes españoles comenzaban cantando en inglés los éxitos del momento, pero paulatinamente fueron introduciendo títulos propios cantados en español. Los focos de desarrollo y difusión de la música pop fueron en primer lugar Madrid y Barcelona, pero su éxito hizo que se organizaran festivales y conciertos en otras capitales de España. 
15 Es también en este periodo cuando el poder adquisitivo de los jóvenes aumenta, dándoles acceso no sólo al transistor sino también a los conciertos, al tocadiscos y a los discos, sobre todo tras la revolución del single. El disco será una manifestación más de la sociedad de consumo (Casas, 1972, p. 14). Por ello no es de extrañar que los medios de comunicación y las compañías discográficas hagan del público joven uno de sus objetivos primordiales.

16 El éxito de los Beatles y de otros grupos anglosajones propulsó el inglés que se convirtió en la letra por excelencia de la música y se impuso paulatinamente como lengua extranjera de todos los establecimientos de enseñanza, desbancando al francés (Irles, 1997, p. 12). Como afirma José María Iñigo ${ }^{5}$ " "en los sesenta el inglés se convirtió en la lengua franca de la modernidad" (Iñigo, 2004, p. 28).

17 En este sentido, el pop español, al incorporar las tendencias más avanzadas de la música occidental, contribuyó a modernizar las costumbres de los jóvenes españoles, que se sentían próximos de sus coetáneos europeos y americanos. Como en EEUU, en Inglaterra y en Francia, también en España nació una conciencia de grupo entre los jóvenes al calor de los ídolos musicales. Con palabras de José María Iñigo "la música y la moda fueron claves para que España compartiera la modernidad en la que llevaba ya instalada unos años antes el resto de Europa occidental. Si política y económicamente España avanzaba con retraso, en música estuvimos a la última desde el primer momento" (Iñigo, 2004, p. 39).

\section{Los pioneros: El Dúo Dinámico}

Ramón Arcusa (1936) y Manuel de la Calva (1937), El Dúo Dinámico, fueron los primeros ídolos de la juventud española ${ }^{6}$. Empezaron actuando en fiestas juveniles y emisoras locales a finales del 1957. Su despegue artístico se produjo en 1958 a raíz de su actuación en el programa "La comarca nos visita" de Radio Barcelona. Hasta ese momento se llamaban los Dynamic Boys, pero el locutor, Enrique Fernández, les dijo que no sabía inglés y los anunció como el Dúo Dinámico. Su actuación fue un gran éxito y prosiguieron su carrera con este nombre. Después de varias actuaciones en la radio ${ }^{7} \mathrm{y}$ en salas de fiestas, firmaron un contrato con la Gramofon-Odeón (posteriormente EmiOdeón), grabando su primer EP en el otoño de $1959^{8}$.

Comenzaron haciendo versiones de éxitos americanos como Adán y Eva de Paul Anka, Hello Mary Lou de Gene Pitney, Bye Bye love de los Everly Brothers pero pronto se lanzaron a componer sus propios temas con los que obtuvieron grandes éxitos: Quince años tiene mi amor (1960); en 1961 quedaron segundos en el Festival de Benidorm con Quisiera ser y los éxitos se sucedieron: Mari Carmen (1961), Perdóname, Lolita Twist, Somos jóvenes (1962), Amor de verano (1963) Esos ojitos negros (1965), canción presentada en el Festival de Eurovisión que quedó en segundo lugar. En 1966 ganaron el primer premio del Festival del Mediterráneo con Como ayer.

20 La imagen de los dos chicos jóvenes, guapos, bien vestidos, simpáticos y españoles se hizo familiar entre la juventud. Llevaban el pelo bien cortado y peinado como los cantantes norteamericanos y fueron los primeros en utilizar el atuendo como seña de identidad. La ropa que más les caracterizó fue el chaleco rojo sin mangas con cuello de pico. Siguieron otros modelos con mangas o sin ellas y otros colores, pero siempre el jersey de pico. 
Con el Dúo Dinámico llegó el rock y el twist. Canciones como Bailando el Twist, Lolita Twist acabaron de afianzar el nuevo baile. Sus discos ofrecían a los jóvenes toda la gama de estilos y tendencias de la música moderna desde el slow rock (para bailar a lo agarrado) como Perdóname al twist y el rock para bailar a lo suelto, dando al mismo tiempo a sus canciones un toque español: Esos ojitos negros, María del Pilar, Balada gitana, Es Maricarmen ${ }^{9} . .$. El hecho de cantar en español ha sido señalado como una de las claves de la promoción de la música española (Ordovás, 1987, p.13). Incluso llegaron a protagonizar varias películas musicales, género en boga en los 1960, lo que significaba la consagración de su popularidad: Botón de ancla (1960), Escala en Tenerife (1964), Búsquenme a esa chica (1964), Una chica para dos (1965).

Como expresión del despertar de la conciencia de la identidad juvenil es sintomática la canción Somos jóvenes.

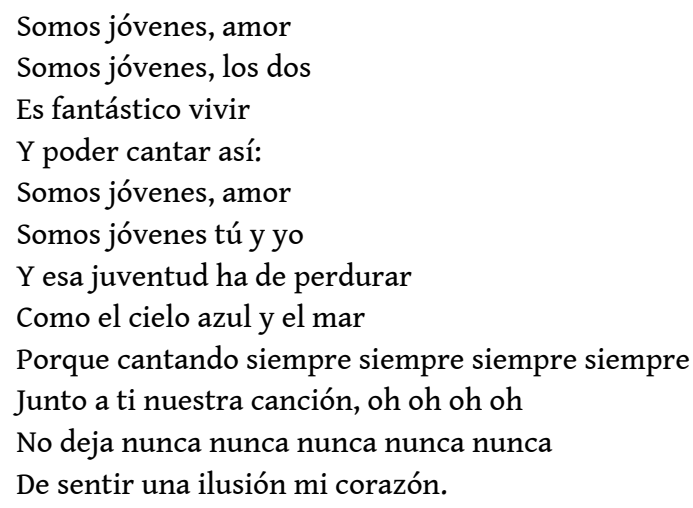

Si nos detenemos en la letra, podemos observar que no tiene un gran contenido programático. Lo único que se afirma es el hecho de ser joven como un valor en sí 'fantástico'; un valor destinado a perpetuarse como el cielo y el mar al que va unido un sentimiento de esperanza que se expresa a través de la música. En definitiva eran unos cantantes jóvenes para un público joven.

Las primeras fans fueron las del Dúo Dinámico. Cuando salían a escena el "clamor continuo y entusiasta hasta el paroxismo hacía retemblar el Palacio Municipal de Deportes de Barcelona" (Ordovás, 1987, p. 13). La revista Fans les dedicó un reportaje La fulgurante vida del Dúo Dinámico ( $\left.{ }^{\text {os }} 24-28,1965\right)$ en el que se daban a conocer los comienzos de su carrera artística y los éxitos cosechados hasta el momento.

Fueron muy populares hasta mediados de los 1960, pero la moda de los dúos no sobrevivió a la ola beat. En el concurso "Los 17 de la Fama" organizado por El Correo de la radio en 1963, El conjunto los Mustang alcanzo el primer puesto por encima del Dúo Dinámico que eran los más famosos hasta el momento. La victoria de los Mustang es sintomática del impacto del nuevo estilo de música británico que hizo proliferar a los grupos con batería y guitarras eléctricas (Ordovás, 1987, p. 27).

\section{El rock en las matinales del Price}

El rock americano tardó en imponerse en el suelo ibérico, a pesar de que los primeros discos de Elvis Presley se editaron en España solo unos meses más tarde que en EEUU. En realidad, ni la radio ni la incipiente TVE le dedicaron especial atención por lo que no causó un gran impacto en el público (Ordovás, 1987, p. 12). Por otro lado, el éxito del 
Twist, más fácil de bailar y la ola beat que se impuso a partir de 1963, sumergieron al auténtico rock que reapareció en la década de los 1980.

Uno de los primeros grupos españoles de rock fue el de Los Estudiantes formado en 1959. Grabaron en la primavera de 1960 su primer disco de rock and roll (Philips). Cuando el grupo se deshizo en 1964, algunos de sus componentes integraron otros grupos que se hicieron famosos como los Pekenikes y los Brincos de quienes hablaremos más adelante.

La difusión del rock en España está ligada a los Festivales de Música Moderna del Price Music Hall, organizados por los hermanos Miguel Ángel y Pepe Nieto los domingos por la mañana ${ }^{10}$. Los organizadores querían realizar en Madrid algo parecido a lo que se hacía en el Olympia de París. Aunque apenas duraron año y medio, por las matinales pasaron los cantantes y grupos de rock que empezaban a darse a conocer y que luego ocuparían los primeros puestos de los superventas: Mike Ríos, conocido más tarde como Miguel Ríos, Los Relámpagos, Los Pekenikes, Los Sirex, Bruno Lomas, Los Mustang, Los Tonys y muchos otros.

El primer concierto tuvo lugar el 18 de noviembre de 1962. En los carteles se anunciaba "un espectáculo de juventud para los jóvenes amantes de la música de nuestro tiempo". Las matinales tuvieron un gran éxito y se formaban grandes colas para comprar las entradas con anticipación (Iñigo, 2004, p. 41). Durante la primera temporada 1962-1963 se organizaron 13 festivales. Los componentes de los conjuntos eran generalmente jóvenes estudiantes entre 16 y 22 años (Fonorama, n 1, 1963).

El entusiasmo de los jóvenes era tal que no pasaron desapercibidos. Comenzaron a aparecer en la prensa comentarios negativos sobre los chicos y chicas que salían por la calle bailando y aullando al ritmo enloquecido del Twist. La música moderna era vista por la sociedad de adultos como patear, berrear y hacer ruido (Pardo, 1988, p. 32) ${ }^{11}$.

31 La revista Triunfo ( ${ }^{\circ} 27,8$ de diciembre de 1962) hizo un reportaje sobre los conciertos del Price, comentando que unos dos mil jóvenes, universitarios, oficinistas y obreros, vibraban con entusiasmo al ritmo de la batería y del Twist. Se subraya el frenesí por la música moderna y la actitud similar de los jóvenes españoles a la de los extranjeros: "El espectáculo, habitual en otras capitales europeas, de desenfreno e incondicional devoción por los ritmos nuevos, se ha visto en su propia salsa en el recinto teatral madrileño. Los jóvenes han respondido al ritmo que electriza hoy día a todo el mundo" (Triunfo, $\mathrm{n}^{\circ} 27, \mathrm{p} .15$ ).

32 Aunque el tono del reportaje traduce el asombro, no sin cierta ironía, ante el entusiasmo de los jóvenes comparable con la afición al fútbol, se puede leer entre líneas una cierta crítica ante las manifestaciones desenfrenadas:

La butaca es como una cárcel para estos muchachos que necesitan moverse, bailar el Twist, gritar, aplaudir [...] Se levantan, chillan, marcan unos compases, se vuelven a sentar; silban cuando un número les gusta [...] ¿Donde vamos a parar? Los chicos se suben por las paredes, mientras les dejan, claro. Quieren más, más... [...] Los dos mil muchachos salen tarareando Speedy Gonzalez. (Triunfo, $\mathrm{n}^{\circ} 27, \mathrm{p} .25$ )

En el diario vespertino Pueblo aparecieron también una serie de artículos con fotos en las que se veían a jóvenes bailando por la calle. Concretamente, en la edición del martes 26 de febrero de 1963, el pie de foto rezaba lo siguiente: "Twist en las calles de Madrid". Seguía un comentario en el que se cuestionaba a esta juventud que ocupaba de manera ruidosa y descontrolada las calles de la capital (Pardo, 1988, p. 52). Las críticas repetidas provocaron la prohibición de los festivales en 1964. 

batería ${ }^{12}$.

\section{El ye-ye}

No cabe duda que el entusiasmo de los jóvenes madrileños por la música moderna creaba una cierta inquietud en la sociedad adulta que no veía con buenos ojos esas modas extranjeras. Al mismo tiempo, las imágenes conservadas en los archivos de TVE sobre estos encuentros y las fotografías publicadas en la prensa muestran una juventud que vibra y disfruta con el rock, el Twist, las guitarras eléctricas y el ritmo de la

El ye-ye surgió en Francia en torno al programa de radio y la revista Salut Les Copains (1962), factores determinantes en la rápida difusión de la música moderna francesa. Como es bien sabido, la expresión 'ye-ye' es la transcripción fonética del inglés 'Yeah', 'Yeah' (Yes), que se intercalaba en las canciones incluso aunque el texto estuviera en francés. El primero en poner de relieve la relación entre los jóvenes ye-ye y Salut les copains fue el sociólogo Edgar Morin en dos artículos publicados en Le Monde el 6 y 7 de julio de 1963 respectivamente. La cadena de radio Europe 1 había organizado un concierto el 22 de junio, en la Place de la Nation en Paris, para festejar la salida del Tour de France. El concierto había sido anunciado por Salut les copains lo que dio lugar a una gran concentración de jóvenes (entre 100 y 150 mil). Morin analiza la fuerza de atracción de ídolos como Johnny Hallyday, Sylvie Vartan... y llama la atención sobre la aparición de una nueva clase de edad con una identidad propia: la generación ye-ye que él identifica con los teenagers, a los que denomina adolescentes a falta de otro término más apropiado para designar a los jóvenes de 13 a 19 años.

El programa de radio Salut Les Copains había empezado en 1959, transmitiendo música americana, que su presentador Daniel Filipacchi traía directamente de los EEUU (Quillien, 2009, p. 15 y ss). A partir de 1960 comenzó a dar a conocer a los jóvenes cantantes franceses. Una de las claves de la popularidad de los cantantes era ser elegido como "chouchou" o favorito de la semana. En el verano de 1962 se podía oír todos los días Tous les garçons et les filles de Françoise Hardy. El programa tuvo un gran éxito entre el público quinceañero y se convirtió en la plataforma musical de cantantes y grupos que acapararon las listas de éxitos de la música francesa. (Quillien, 2009, p. 20). En los primeros puestos de Salut les copains aparecían invariablemente Johnny Hallyday, Eddy Mitchell, Claude François, Sylvie Vartan, Sheila, Françoise Hardy, France Gall. Entre los extranjeros, Petula Clark y los Beatles fueron los reyes de la canción moderna.

La idea de lanzar una revista fue motivada por los mismos oyentes que reclamaban fotos y noticias de los artistas que escuchaban en la radio. El primer número, a título experimental, fue un especial de verano (julio-agosto) de 1962. Su éxito fue rotundo y alcanzó en un año una tirada de un millón de ejemplares mensuales ${ }^{13}$.

La ola ye-ye se propagó rápidamente en España y fueron sus portavoces las revistas Fonorama y Fans. La expresión 'ye-ye' fue introducida por Fonorama ( $\mathrm{n}^{\circ} 4$, febrero de 1964, p. 19) ${ }^{14}$. Fans (1965) se presentó como la revista de la canción indispensable para las chicas ye-ye. Las imágenes de las cantantes francesas, en particular Sylvie Vartan considerada la reina ye-ye, ocuparon gran parte de las páginas de ambas revistas.

9 En un primer momento, la moda ye-ye afectó sobre todo al mundo de las fans más que al de las cantantes, ya que ninguna de las españolas respondía bien al modelo francés ${ }^{15}$. La primera cantante ye-ye hispana fue Karina (Isabel Llaudes 1943-), aunque su carrera 
se desarrolló en la segunda mitad de los años 1960 con un retraso de unos cuatro o cinco años con respecto al movimiento francés. Su primer gran éxito como solista fue Me lo dijo Pérez de Alberto Cortez que quedó en segunda posición del II Festival de Mallorca en 1965. También fue uno de sus éxitos la versión española de Poupée de cire de France Gall ${ }^{16}$.

Karina era rubia como Sylvie Vartan, tenía ojos claros y un cierto aire de niña. De 1967 a 1970 estuvo omnipresente en las listas de éxitos. Sus canciones tenían bonitas melodías y ritmo suficiente para entusiasmar a los jóvenes. En 1966 obtuvo la Medalla de Oro como Mejor Cantante "ye-ye".

La imagen de la chica ye-ye se hizo popular en España gracias a la canción de Antonio Guijarro y Augusto Algueró interpretada por Conchita Velasco (1939-) en la película Historias de la televisión de José Luis Sáez de Heredia. La chica ye-ye se convirtió en el gran éxito del verano 1965 y una de las canciones más populares durante 1966 (Vázquez Montalbán, 2000, p.14). La canción, 40 años después, sigue presente en la memoria sentimental de los españoles como emblema musical de los $1960^{17}$.

Ser 'ye-ye' en los años 1960 era sinónimo de "joven y moderno" en la manera de ser, de vestir, de cantar y de bailar. En este sentido puede ser ilustrativa una entrevista a Miguel Ríos, cantante de rock, publicada en Fans:

El cantante español de 22 años declara que sus cantantes preferidos son Elvis, los Beatles y Frank Sinatra. A la pregunta ¿eres un ye-ye? Responde: "Vivo la época y, naturalmente, en estos momentos vivimos la hora ye-yé”. ¿Qué es ser ye-yé? “Tener una forma de ser, que lo mismo puede evidenciarse cantando, que escribiendo, o bailando. Yo creo que el ye-yé es aquel joven que aporta algo nuevo, y a la vez bueno." (Fans, $\mathrm{n}^{\circ}$ 32, 1966)

Como se puede ver en las respuestas del cantante la noción de 'ye-ye' no tenía un sentido muy preciso pero se identificaba con ser joven y con la música nueva, cantando y bailando. El tema de la juventud era esencial para ser ye-ye y la música debía tener ritmo, ser alegre y divertida.

Las "cartas a Fans" reflejan a menudo la conciencia de una identidad como jóvenes yeye. Así por ejemplo una lectora de Fans comenta: "Soy una chica yé-yé y me enorgullezco de ello. Por esta razón, creo que habré sido la primera en comprar vuestra revista y no tengo más que felicitaros por ella. ¡Es estupenda! Sobre todo la idea de haber puesto en la página central una foto a todo color de los astros." (Fans, $\left.n^{\circ} 4,1965\right)$

Otra lectora se considera ye-ye porque tiene 14 años. En su opinión, "lo único que caracteriza a los yé-yés es su juventud díscola, inadaptada, rebelde, alocada o lo que sea" (Fans, no 33, 1966).

La música ye-ye trajo consigo una forma de vestir que se concretizó en el atuendo femenino de los pantalones y la minifalda. Las revistas como Fonorama y Fans tenían una página dedicada a la moda ye-ye. La batalla de los pantalones en la moda femenina fue un paso más en el deseo de emancipación de la mujer y de la reivindicación de igualdad con el hombre en la sociedad. Se puede decir que Fonorama y Fans fueron el escaparate de la moda ye-ye en España.

Una buena expresión del ye-ye hispánico y de lo que se ha llamado el cine pop es la película Megatón ye-ye, dirigida por Jesus Yagüe (1965, DVD 2009), en la que actuaban Mochi, María José Goyanes y el conocido grupo Micky y los Tonys ${ }^{18}$. En la película se desarrollan dos historias paralelas. Por una parte, una historia romántica un poco cursi 
entre Mochi, cantante, y María José Goyanes, joven provinciana de aspecto tradicional que marcha tres meses a Paris para aprender francés. La otra historia es la del conjunto Micky y los Tonys que intenta abrirse paso en el mundo de la canción ye-ye a través de los concursos, intentando firmar un contrato para hacer una película. La otra protagonista femenina de la película es la hija de un productor de cine y representa a la chica moderna, liberada y ye-ye.

La película refleja la Beatlesmanía galopante de los años 1960 y el impacto de la música extranjera en España: en la tienda de discos donde Juan, (Mochi) encuentra por primera vez a Elena (María José Goyanes), se ven discos de los Beatles y de los Rolling Stones. En el teatro donde tiene lugar el concurso de grupos, el decorado de fondo presenta fotos de cada uno de los Beatles, Rita Pavone y Sylvie Vartan. A través de la película se puede ver el entusiasmo de los jóvenes por los conjuntos y los festivales. La película muestra el itinerario obligado para triunfar en la música: concursos, radio, televisión y contratos con las firmas discográficas ${ }^{19}$.

En Megatón ye-ye se afirma también el deseo de libertad y de independencia de los jóvenes con respecto a sus mayores. El ye-ye, como dice Mochi en una entrevista, es una cuestión de época. Por ello es lógico que los adultos no lo acepten ni lo entiendan. La película muestra la ruptura entre los jóvenes y el mundo de los adultos a través de su música y su forma de bailar, aunque se trata de una ruptura relativa. Así por ejemplo Mochi, Micky y los Tonys acuden al padre de la otra protagonista femenina, para que les ayude en el lanzamiento de su carrera artística.

51 La moda ye-ye no duró muchos años. Se puede situar su cenit en 1965 y su declive en 1967. A continuación vino la moda hippie que introdujo una nueva estética y una nueva ideología mucho más contestataria e inconformista. Probablemente el movimiento peace and love, aunque menos mayoritario, no hubiera podido abrirse paso sin la ruptura iniciada por los jóvenes ye-ye.

\section{El beat británico: los conjuntos}

La revolución musical iniciada por los Beatles hizo que los grupos españoles se decantaran rápidamente por el beat británico y contribuyó a una gran explosión de conjuntos. Su llegada a España en julio de 1965 para actuar en Madrid (Plaza de las Ventas) y Barcelona (Plaza Monumental) fue todo un acontecimiento ${ }^{20}$. Era la primera y única vez que vinieron a España pero ya se habían convertido en los ídolos de la gente joven, imponiendo un nuevo look y una nueva forma de hacer música. La revista Fans le dedicó un amplio reportaje durante 8 números seguidos, poniendo a conocimiento de sus lectores los más mínimos detalles de La verdadera historia de los Beatles ( ${ }^{\text {os }} 15-23$, 1965).

Los primeros grupos del beat hispánico se formaron en Barcelona y en Madrid, pero rápidamente surgieron conjuntos por toda la geografía española hasta el punto de que no había ciudad o pueblo que no tuviera su conjunto ${ }^{21}$. Festivales, revistas, periódicos musicales, publicaciones de los clubs de fans de la época, crearon el clima propicio en el que florecieron los primeros grupos: Los Salvajes, Lone Star, Los Sirex, Los Mustang en Barcelona. Paralelamente en Madrid, desde 1960, tienen lugar las grabaciones de los primeros grupos de música rock: Los Estudiantes, los Pekenikes, los Sonor y los Relámpagos. 

alcanzaron un éxito fulgurante en sus dos años de existencia (Pardo, 1988, p. 65). El grupo se creó en 1964 con miembros procedentes de otras formaciones como Fernando Arbex que provenía de los Estudiantes, Junior de los Pekenikes, Juan Pardo de los Vándalos y Manuel González que era el único que no venía de un grupo anterior. El sello Novola de la compañía Zafiro apostó por lanzar a los Brincos como conjunto beat típicamente español. Todos ellos eran estudiantes, aunque abandonaron los estudios para dedicarse a la música.

Comenzaron cantando en inglés y haciendo versiones de éxitos extranjeros, pero pronto impusieron sus propias canciones. En su primer LP de 12 canciones, siete títulos son en inglés y cinco en español. Rápidamente se irán decantando hacia lo genuinamente español, convirtiéndose en la gran fuerza pop del país. Flamenco (1964) fue un éxito arrollador porque supo combinar el pop inglés con lo español. El segundo LP de los Brincos, confirmó la popularidad del grupo con otras doce canciones de gran calidad: Borracho, Tú me dijiste adiós, Un sorbito de champán, situándose en el $n^{\circ} 1$ del Hitparade. calidad vocal y un gran sentido de la melodía pop. Su éxito mostraba que los grupos nacionales también podían competir con los extranjeros. En este sentido es muy interesante el comentario a la primera aparición de los Brincos en la revista Fans:

Un conjunto con categoría: Los Brincos. [...] Los Brincos se han convertido en un tiempo récord en uno de los conjuntos españoles más importantes. Sus discos han tenido impacto entre el público joven y han cruzado, incluso, nuestras fronteras. Su canción Flamenco, creación suya, se encuentra entre las más destacadas interpretaciones del año. (Fans, $n^{\circ} 11,1965$ )

El vestuario constituyó una de las imágenes de marca de Los Brincos. Una de sus prendas prototípicas fueron las capas españolas. Eran unas capas negras con el forro color sangre de toro. Completaba el atuendo unos zapatos con hebilla o cascabeles en el empeine. Esta imagen reforzaba la identidad española del conjunto. La prensa musical de la época refleja el entusiasmo de los jóvenes por un conjunto moderno y español. Así la carta de una lectora de Fans que ensalzaba a los Beatles y criticaba a los Brincos, provocó una oleada de protestas en favor del conjunto español (Fans, $\left.\mathrm{n}^{\circ} 13,1965\right)$. En el número 15, otra lectora reclama más atención a los cantantes españoles:

Más españolismo. ¿Qué pasa con los cantantes españoles? Hay excelentes conjuntos y buenos compositores, pero no nos detenemos a escucharles. No salimos de los Beatles, a los que tenemos hasta en la sopa. Ya es hora de salir de esto. Merece la pena saber que en España tenemos a los Sirex, Raphael, Los Brincos, José Guardiola, etc., que, aparte de que cantan formidablemente, son compatriotas nuestros.

De 1964 a 1966 grabaron 9 singles, 5 EP y 2 LP, convirtiéndose en el primer grupo pop español. Se les oía en todas las emisoras de radio y ocuparon un lugar destacado en las revistas. Grabaron discos en Francia, Italia, Inglaterra y otros países, pero su carrera fulgurante, como la de muchos conjuntos, se truncó con la separación de Juan y Junior en $1966^{22}$. 


\section{Conclusión} permite establecer algunas consideraciones finales. En primer lugar, podemos observar que el nuevo estilo de música se difundió con una fuerza y rapidez similares a las de los países vecinos, a pesar de la falta de libertades democráticas y del retraso económico de España.

60 A esta rápida difusión contribuyeron los medios de comunicación, principalmente la radio, la industria discográfica y el cine. En todas las grandes emisoras se crearon programas en los que se emitía música para los jóvenes, fundamentalmente en inglés. Probablemente, la ausencia de mensaje político favoreció el apoyo decidido de los medios de comunicación a la música moderna. Para la radio era también una manera de afirmarse frente a la Televisión que estaba irrumpiendo con fuerza en todos los hogares españoles ${ }^{23}$. Los programas de radio, basados en la presentación y comentario de los últimos éxitos discográficos, contribuían al desarrollo de la industria discográfica, dando al mismo tiempo una imagen de una juventud moderna, cercana a la de sus coetáneos europeos. Las firmas discográficas españolas, Hispavox, Emi-Odeon, Novola, tras el éxito de ventas de los discos de los Beatles, también se lanzaron a la promoción de los conjuntos nacionales. Las películas musicales, por su parte, contribuyeron de manera determinante a la popularidad de los ídolos y de la moda ye-ye.

Su rápida expansión y su puesto cada vez mayor en la vida de los jóvenes hicieron de la música el cauce privilegiado de expresión de la juventud, contribuyendo a crear, como en los demás países occidentales, la conciencia de la identidad "joven" frente a la sociedad adulta. Esta identidad joven, abierta a las modas extranjeras, irá cobrando fuerza a lo largo de la década, manifestándose no solo a través de la música, sino también en la forma de vestir, en nuevas formas de divertirse y en definitiva dando lugar a cambios de mentalidad que serán patentes en la década siguiente.

\section{BIBLIOGRAFÍA}

Aguilera Moyano Miguel, “De la autarquía a la democracia: La Radio española en los años sesenta y setenta", en T. Álvarez, Historia de los medios de comunicación en España. Periodismo, imagen y publicidad (1900-1990), Barcelona, Ariel, 1989, p. 289-303.

ALONSo Celsa, "El beat español: entre la frivolidad, la modernidad y la subversión", Cuadernos de música iberoamericana, $\mathrm{n}^{\circ} 10,2005$, p. 225-254.

ALVAREZ José Luis, Los Beatles en España, Lobo Sapiens, s.l., 2009.

BERMÚdez Silvia y PÉREZ Jorge, 2009, “Introduction: Spanish Popular Music Studies”, Journal of Spanish Cultural Studies, $\mathrm{n}^{\circ}$ 10/2, p. 127-133.

CAMPoy César, Érase una vez los Brincos y Juan \& Junior, Barcelona, Midons, 2006.

CASAS Ángel, 45 revoluciones en España (1960-1970), Barcelona, Dopesa, 1972.

ILCEA, 16 | 2012 
Colmeiro José, "Canciones con historia: Cultural identity, historical memory, and popular songs", Journal of Spanish Cultural Studies, $\mathrm{n}^{\circ}$ 4/1, 2003, p. 31-45.

De CASTRO Javier, ORó Alex y RUIZ Josep M., Quan Lleida era ye-ye. Musica moderna i societat (1960-1975), Pagès editors, 2005.

Fans, la revista de la canción, $\mathrm{n}^{\text {os }} 1-31,1965$.

Fonorama, $\mathrm{n}^{\text {os }} 1-10,1963-1964$.

FoucE Héctor, El futuro ya está aquí. Música pop y cambio cultural, Madrid, Velecío Editores, 2006.

GÁMEZ Carles, Cuando todo era yé-yé, la música era pop y tu cantabas Bang-bang, Valencia, Midons, 1997.

IÑIGO José María, Cuando éramos jóvenes. España años 60: recuerdos de una década apasionante, Madrid, La esfera de los libros, 2004.

IRLES Gerardo, Solo para fans: la música ye-ye y pop española de los años 60, Madrid, Alianza Editorial, 1997.

Megatón ye-ye, película dirigida por Jesús Yagüe, prod. Eva film/ Mundial Film, 1965.

MejÍAs Ignacio, La identidad juvenil desde las afinidades musicales, Madrid, Injuve, 2001.

ORDOVÁs Jesús, Historia de la música pop española, Madrid, Alianza Editorial, 1987.

PARDo José Ramón, Historia del pop español, Madrid, Rama Lama Music, 1988.

PedRero EstebAn Luis Miguel, La radio musical en España. Historia y análisis, Madrid, Instituto Oficial de Radio y Televisión, 2000.

QUILLIEN Cristophe, Nos années «Salut les copains » (1959-1976). Préface de Jean-Marie Périer, Paris, Flammarion, 2009.

Salut les copains, $\mathrm{n}^{\text {os }} 1-65,1962-1967$.

¿Te acuerdas?, TVE1, 18/11/2010, <http://www.rtve.es/alacarta/videos/te-acuerdas/acuerdasteatro-circo-price/934657/>

Triunfo, $\mathrm{n}^{\circ}$ 27, 8 de diciembre de 1962.

VAZQUEZ MonTALBÁN Manuel, Cancionero Musical del franquismo, 1939-1975, Barcelona, Editorial Crítica, 2000.

\section{NOTAS}

1. Existe una abundante producción, en gran parte descriptiva, sobre esta música joven que se impuso como un alud arrollador en los años 1960. Con un tono más o menos nostálgico se suele evocar cómo la juventud española incorporó las tendencias musicales extranjeras que marcaron esta época. Por otro lado, los trabajos que se inscriben dentro de los Spanish Cultural Studies o más precisamente los Spanish Music Popular Studies se han centrado más en la significación política de las canciones durante la época franquista o en la movida y la época dorada del rock hispánico de los años 1980. En la bibliografía mencionada al final del artículo indicamos algunas referencias sobre estos temas.

2. No podemos dejar de mencionar algunos de los programas creados para los jóvenes y la nueva música: Discomanía (1960) en la cadena SER; Nosotros los jóvenes (1960) en La Voz de Madrid dirigido por Miguel Ángel Nieto; Discomoder (1961) en Valencia; La hora de los conjuntos, en Radio 
Juventud, Vuelo 605 (1963) en Radio Peninsular, Discodial (1963), presentado por Marisol Tomás Lázaro en Radio Juventud, etc.

3. <http://www.lne.es/sociedad-cultura/2010/04/22/caravana-angel-alvarez/ 904454.html> [consultado el 17/06/2011].

4. Entre los famosos que aparecen en las distintas secciones podemos destacar a los Beatles, los Rolling Stones, Cliff Richard, Elvis Presley, Paul Anka, Frank Sinatra, Petula Clark, Rita Pavone, Adriano Celentano, Gigliola Cinquetti, Gianni Morandi, Sheila, Aznavour, Sylvie Vartan, Johnny Halliday, Adamo, Los Surf, Françoise Hardy, Claude François, Richard Anthony, Alain Barrrière. Entre los españoles, El Dúo Dinámico, Los Brincos, Conchita Velasco, Los Sirex, etc.

5. José María Iñigo (1942-) es un periodista, presentador de radio y televisión que comenzó muy joven (18 años) como corresponsal en Londres para los programas musicales de la cadena SER. En la capital inglesa tomó contacto con los movimientos de música beat de los que se hizo embajador a su regreso a España. Animando programas de radio y de televisión, como El Musiquero, El gran Musical, Los 40 Principales y Último grito, contribuyó a la difusión de la música moderna. En 1972 dirigió el programa de televisión Estudio abierto, que le hizo popular en todos los hogares españoles. Al mismo tiempo, José María Iñigo constituye un testigo excepcional de la recepción de la música extranjera en España y su influencia en la música nacional en los años 1960.

6. Eran dos chicos jóvenes que trabajaban como delineantes en el Departamento Técnico de diseño de fabricación de motores de aviación de Elizalde S.A., empresa de Barcelona.

7. Radio Juventud, Radio Nacional Fantasía, y Radio Barcelona El show de las 2.

8. <http://www.duodinamico.com/Adelante.htm> [consultado el 1/06/2011].

9. Entre 1959 y 1965 sacaron 31 EP con el sello Emi-Odeón.

10. Miguel Ángel Nieto era estudiante de Ciencias de la Información y con el tiempo llegaría a ser un conocido periodista. Desde el principio apostó por la música joven. En 1963 fue director del programa musical Nosotros los jóvenes en Radio España y fue redactor jefe de la revista Fonorama (1963-1968). Su hermano Pepe era el batería del grupo los Pekenikes. En 1970 inició su carrera como compositor de música de cine y televisión, campo en el que ha obtenido varios galardones. Actualmente es profesor de sonido en la Escuela de Cine y Audiovisuales de Madrid ECAM.

11. Si se tienen en cuenta las críticas publicadas en la prensa a raíz de la concentración de jóvenes en la Place de la Nation el 22 de junio de 1963, no es de extrañar que las mismas manifestaciones de jóvenes suscitaran reacciones similares en la prensa española.

12. Las matinales del Price se convirtieron con el paso de los años y la mirada retrospectiva en un mito de la eclosión de la música pop en España. ¿Te acuerdas?, TVE1, 18/11/2010, <http:// www.rtve.es/alacarta/videos/te-acuerdas/acuerdas-teatro-circo-price/934657/> [consultado el 20-6-2011].

13. El programa dejó de emitirse en 1969.

14. El artículo se titula "El yé-yé".

15. Por falta de espacio no podemos detenernos en las representantes de la canción ligera española de estos años.

16. Karina empezó grabando para RCA y después firmo un contrato con Hispavox con quien grabó 8 EP y 6 singles sólo en la década de los 60. También participó en cuatro películas: Escala en Hi-fi, Los chicos de Preu, La chica de los anuncios y La máquina de hacer pop entre 1963 y 1970.

17. Conchita Velasco fue sobre todo actriz de cine más que cantante, pero interpretó en varias películas el papel de una cantante ye-ye.

18. Mochi, nombre artístico de Juan Erasmo Mochi (1943-), es un cantante español que sin llegar a alcanzar las cimas del hit parade fue uno de los protagonistas de la revolución musical. Su rostro era conocido sobre todo como presentador del programa de televisión Escala en hi-fi, iniciado en 1961, que presentaba en play back los éxitos musicales del momento. A partir de Megatón ye-ye comenzó una carrera como solista. María José Goyanes 1948-) es una actriz de cine y televisión, consagrándose fundamentalmente al teatro. También participó en sus inicios en el programa 
Escala en Hi-fi. El grupo Micky y los Tonys estaba formado por cuatro instrumentistas (Tony de Corral, guitarra solista, Fernando Argenta, guitarra de ritmo, Juan Fuster, bajo y Enrique Moddell, batería) y un vocal: Micky (Miguel Ángel Carreño). Comenzaron su carrera en 1960. Su éxito creciente explica que fueran elegidos para actuar en Megatón ye-ye. La banda sonora de la película fue compuesta integralmente por el grupo. Realizada en blanco y negro se estrenó el 14 de septiembre de 1965.

19. La compañía discográfica 'Zafiro', a través de su sello juvenil ‘Novola' realizó la grabación de la banda sonora de la película y también un EP y un 'single' de Micky y Los Tonys, a finales de 1965.

20. Un año antes (enero-febrero de 1964) habían realizado una gira por Francia obteniendo un gran éxito en el Olympia.

21. Se suele comentar que Barcelona fue pionera en la introducción de las nuevas tendencias de música extranjera y es indudable que había una gran vitalidad y dinamismo entre los grupos de música moderna, pero esto no debe ocultar que también en Madrid se produjo la eclosión de la música pop con los primeros discos y conciertos de rock. Entre los conjuntos más famosos podemos citar a Los Sirex en Barcelona cuyas actuaciones eran un gran éxito. Entre sus títulos más famosos Si yo tuviera una escoba, Que se mueran los feos. Los Mustang, otro grupo de Barcelona, alcanzaron un gran éxito cantando todos los éxitos de los Beatles en español. Fonorama, $\mathrm{n}^{\circ} 17$, octubre de 1965, publica una lista de más de 900 conjuntos distribuidos por casi todas las ciudades españolas.

22. Juan y Junior continuaron su carrera musical formando un dúo en febrero del 1967. Hasta su separación en 1969 obtuvieron grandes éxitos con sus 6 singles. El grupo de los Brincos continuó con nuevos componentes (Vicente Jesús Ramírez, sustituido más tarde por Miguel Morales, y Ricky Morales, ambos hermanos de Junior) alcanzando también grandes éxitos en la segunda mitad de los 1960 pero sin llegar a la mítica popularidad de la primera formación. El grupo se disolvió en 1970 tras la grabación de su último disco: Mundo, demonio y carne.

23. Televisión española había comenzado oficialmente en 1956, pero su auténtico despegue y época de desarrollo tuvo lugar entre 1962 y 1964.

\section{RESÚMENES}

El desarrollo económico de España a lo largo de los años 1960 marca un punto de inflexión en la evolución del franquismo. Si desde el punto de vista político el Movimiento (ideología política del franquismo) permanece inamovible, las libertades cotidianas propias de una sociedad de consumo irán creciendo paulatinamente. La llegada estival de turistas contribuirá a una serie de cambios en la mentalidad y en el comportamiento de los españoles. Una de las manifestaciones del deseo de la sociedad española de acercarse al estilo de vida de los países occidentales es la recepción de la música pop: el rock americano, la música ye-ye francesa y el beat británico. La adopción de los modelos musicales extranjeros por los jóvenes españoles marca una ruptura con la generación precedente. El propósito de este artículo es presentar las diferentes tendencias de la música pop en la primera mitad de la década de los 1960 y su impacto en los jóvenes a través de los medios de difusión - radio, prensa y cine - que contribuyeron a su desarrollo.

Spain's economic development throughout the 1960s marks a turning point in the evolution of Franco's regime. Although the Movement (the political ideology of Francoism) remained 
immovable from a political point of view, individual freedoms associated with the consumer society nevertheless gradually increased throughout the decade. The annual arrival of summer tourists also contributed to profound changes in the mentality and the habits of Spanish society. The desire in Spanish society to approach the way of life of modern Western societies was visibly present especially in the reception of Pop Music: American Rock, French Yé-Yé music, and British Beat. The adoption of foreign musical models by the majority of Spanish youth marked a major break with the previous generation. The aim of this paper is to present different trends in Pop Music in the first half of the sixties and their impact on the Spanish youth, as well as the mass media - radio, press and cinema - which contributed to its development.

\section{ÍNDICE}

Palabras claves: Brincos, Dúo Dinámico, España años 1960, música pop, música y medios de comunicación, Price Music Hall, ye-ye

Keywords: Brincos, Duo Dinamico, Mass Media and Music, Pop music, Price Music Hall, Spain sixties, ye-ye

\section{AUTOR}

\section{PALOMA OTAOLA GONZALEZ}

Université Jean Moulin - Lyon 3 ; IETT (Institut d'Études Transtextuelles et Transculturelles) 